NIoma 2016, 34(1), 23-31

Revista de Psicologia, Ciències de l'Educació i de l'Esport

ISSN: $1138-3194$

Copyright (c) 2016

www.revistaaloma.net

\title{
La innovació educativa a la Universitat i el nou rol docent
}

Jordi Riera i Romaní

Universitat Ramon Llull

Rebut: 31-1-2016

Acceptat: 27-2-2016

Resum. Al llarg d'aquest article es revisa el concepte d'innovació vinculat a qualsevol professió, les seves accepcions i implicacions de caràcter deontològic. Aquesta introducció ens permet entrar de ple en la innovació a l'àmbit educatiu i les coordenades de màxima actualització psicopedagògica basades en evidències, en el desplegament de la tasca docent a qualsevol etapa educativa i específicament en el nivell universitari. Així mateix es revisa l'estat de la formació inicial i permanent pel desplegament d'aquesta funció professional. Finalment, es recuperen diversos autors i els estudis més recents al voltant de la prospectiva de l'educació i de la tasca docent a curt, mitjà i llarg termini, fent l'anàlisi derivat d'aquestes previsions, i com tot això impacta de ple en l'exercici professional docent.

Paraules clau: innovació educativa; rol docent; innovació docent; ensenyament-aprenentatge; Universitat

\section{Educational innovation at the university and the new role of professors}

Summary. This article features a new look at the concept of innovation as regards any given profession, in terms of the concept's meaning and its ethical implications. This introduction will allow us then to delve into innovation in the educational sphere and the locus of the latest evidence-based psychopedagogy, and take a look at the performance of teaching tasks at all educational levels, but specifically at the university level. In addition, the article provides an overview of the current state of initial teacher training and continuing education in the carrying out of this professional function. Finally, there is a review of the work of several authors and of the most recent studies related to the future prospects for education and the work of teachers in the short, medium and long term, with an analysis derived from these predictions and a discussion of their overall impact on practices in the teaching profession.

Keywords: Educational innovation; role of the teacher; innovation in teaching; teaching and learning; university

Correspondencia

Jordi Riera i Romaní

Universitat Ramon Llull

Facultat de Psicologia, Ciències de l'Educació i de l'Esport

Blanquerna

Email: jordirr@blanquerna.url.edu 
"Aparentemente, no pasa nada. Vemos a nuestros educandos de la sociedad hiperconectada en su perpetuo soliloquio con el móvil o concentrados en alguna pantalla - ¿qué mirarán?- en vez de tomar apuntes. Notamos su renuencia a la comunicación convencional y su seducción por los estímulos visuales, su propensión a hacer varias cosas a la vez, su facilidad para extraer de los artilugios tecnológicos utilidades que ni sospechábamos que existieran. Los vemos, pero hacemos como si todo eso no afectara a su forma de aprender. Seguimos dándoles clase igual que otros hicieron con sus padres. Nada, en la mayoría de las aulas universitarias, parece denotar urgencias de cambio.»

Francisco Longo (2015)

\section{La innovació educativa a la Universitat: el nou rol docent}

Qualsevol ofici, ocupació o professió amb vocació de servei a la societat i que respecti el seu propi codi deontològic -el tingui o no formalitzat- assumeix la voluntat sostinguda i permanent en el seu temps històric, present i futur, de restar amatent a tota millora possible, actualització, canvi o fins i tot transformació, en el desplegament d'aquelles missions, funcions i tasques que li són pròpies per l'encàrrec social que rep en el moment d'esdevenir una tasca «professional». Per tant la innovació esdevé un deure deontològic consubstancial al mateix naixement d'un corpus professional.

\section{La innovació: dues cares de la mateixa moneda}

És evident que aquest primer principi fonamental i fonamentador de l'esdevenir professional pren rellevància progressiva en el temps i en tots els casos de les professions més consolidades, ja sigui el cas de la medicina, on justament l'actitud permanentment investigadora i innovadora de la professió és la que històricament ha generat successius avenços i innovacions que han salvat progressivament en el temps milions de vides humanes, ja sigui el cas de les enginyeries de qualsevol àmbit d'especialització, on els avenços i les innovacions de les quals ens han portat a diverses revolucions sociotecnològiques i a la superació quasi màgica, en molts casos, de multitud de problemes o reptes antics que es consideraven gairebé irresolubles segles o només dècades enrere. Però resulta que també professions o ocupacions de curt recorregut formatiu o exigència prèvia per accedir-hi, com pot ser la d'un taxista, aposten per la innovació: ¿quin taxista avui no s'està plantejant incorporar-se o adherir-se a alguna de les noves plataformes tecnològiques en forma d'APPs per a smartphones per a la sol-licitud digitalitzada del servei de taxi des del mòbil, intuint el risc que li suposaria quedar «fora» de la concepció del servei per part d'un bon nombre de clients actuals -i de la majoria en un futur molt pròxim-si no s'incorpora a aquest tipus d'innovacions, assumint progressivament els canvis culturals que tot això suposa?
La innovació professional, doncs, l'hem d'entendre en primer lloc i en una primera accepció com la natural i obligada incorporació a l'acció professional quotidiana dels progressius avenços cientificotecnològics de les ciències que la fonamenten, i resultaria un incompliment del deure professional desconèixer llur evolució -i per tant un incompliment deontològic- en la mesura que estaria impactant directament i en negatiu en el servei que oferim a la societat mateixa que va consolidar la seva necessitat.

En segon lloc, però, no voldria deixar de referir-me aquí a la concepció de la innovació professional com a actitud de reflexió-acció entorn de la pròpia tasca, entenc que consubstancial també a l'origen de qualsevol professió. Només des d'aquesta posició amatent i conscient de la necessitat de reflexionar entorn dels problemes (millor dit, «reptes») concrets i més generals que afrontem en el nostre dia a dia i de ser-ne bons observadors, sistemàtics i curosos en aquesta reflexió, podem millorar i avançar en el servei que prestem com a professionals a la societat. Una reflexió-acció que rau en l'autocrítica constructiva i analítica al voltant de la nostra intervenció professional, per avançar «per a» $\mathrm{i}$ «amb» els altres en la millora dels resultats i de la idoneïtat de la tasca professional que desenvolupem. Un estil reflexiu que ja presideix el moment previ a l'acció, que se sosté durant i després de l'acció, i fins i tot en el moment d'avaluar la mateixa reflexió (meta-reflexió).

Però aquest caminar reflexionant al voltant de l'acció no està exempt d'obstacles i desviacions. Quan la reflexió passa per sobre dels fets i no compromet l'acció ni es concreta en la seva millora, pot fins i tot esdevenir un obstacle per a la innovació. El quietisme o conservadorisme professional pot pertorbar el procés reflexiu inoculant únicament l'emoció del «reflexionar pel reflexionar», hipotecant la millora real de l'acció que requereix interpel-lar-se, dinamitzar-se i reconstruir-se regularment. I a aquesta desviació, se n'hi pot sumar una altra: la de reflexionar, però sobre els altres. Així, és freqüent que s'acabin realitzant infinitud de reunions de diferent calatge o objectius institucionals, on els professionals sucumbeixin a la temptació de reflexionar sobre la manca de compromisos dels altres «actors», i no sobre la seva pròpia responsabilitat.

La història n'està plena, d'exemples en els quals justament la ceguesa o negligència defensiva gremial de no voler procedir a canvis -innovacions o transformacions necessàries i demandades per la societat a un col-lectiu professional concret- ha portat a la seva progressiva desaparició més enllà que aquest es considerés a ell mateix «imprescindible». Al final la història s'encarrega de posar tothom al seu lloc. I, sovint, la força de les permanentment renovades demandes i necessitats socials és molt més tsunàmica que la contraforça de les resistències absurdes a l'avenç de les ciències i demandes de la societat mateixa.

En l'àmbit educatiu i d'acord amb nombroses investigacions, es demostra que, quan un equip docent aconsegueix incorporar de manera sistemàtica-abans, durant $i$ després de l'acció- processos de supervisió vin- 
culats a successius cicles d'acció-reflexió entorn de la seva praxi professional -individual i col-lectiva-, assoleix canvis i innovacions sòlides plenes de sentit al voltant de les seves concepcions i pràctiques educatives. Preparant-se per a l'acció educativa, reflexionant sobre els seus propòsits i resultats anteriors, aconsegueixen orientar amb més efectivitat l'èxit de les seves noves accions. Reflexionant mentre les estan desenvolupant, exerciten també la seva capacitat metacognitiva i autoreguladora de tal manera que això els fa possible monitorar l'acció mateixa i corregir les desviacions o errors introduiits, reorientant-se millor cap als resultats desitjables.

Aquesta actitud autocrítica dirigida per l'activitat metacognitiva i autoreguladora, esdevé sempre una enorme oportunitat de creixement personal i institucional. Els experts assenyalen que justament aquest comportament és el que diferencia un professional expert d'un de novell; també el que diferencia una organització que opta per la qualitat i millora permanent, d'una altra que es conforma; diferencia també un centre educatiu -tant se val el nivell formatiu al qual pertanyi-merament tecnico-reproductor, adoptant rols que converteixen directius i docents en mers operadors o peons, respecte d'un centre educatiu que revisa, actualitza i transforma periòdicament el seu projecte educatiu des de la reflexió rigorosa per a la millora educativa i, per tant, per a la millora de la societat.

Aquesta doble accepció, doncs, entorn del concepte d'innovació professional de caràcter ontològic i central en el desenvolupament de qualsevol professió -i entre elles la docent- no solament no pot ser ignorada per cap col-lectiu o individualitat professional, sinó que el fet d'obviar-la o menystenir-la en el tasca quotidiana hauria de ser considerat una negligència rellevant, i en tots els casos hauria de ser objecte de formació competencial profunda, de caràcter transversal i interdisciplinari al llarg de qualsevol itinerari formatiu que desemboqui en l'assumpció final d'un rol professional.

Així, doncs i en síntesi, l'actitud innovadora fonamentada i rigorosa d'un cos professional, basada d'una banda en la màxima actualització del cos disciplinari que li és propi i la sustenta, combinadament amb el desig de millora sostingut, basat en l'assumpció dels reptes quotidians i la reflexió sistemàtica al voltant d'aquests, és -o hauria de ser- una característica estructural de qualsevol gremi i doble objectiu central de qualsevol formació professional, sigui quin sigui el seu nivell MECU ${ }^{1}$.

És, doncs, a partir d'aquest principi fonamental que ens exigeix a tots un alt nivell de consciència professional com a docents o educadors -en el nostre cas-i que

${ }^{1}$ MECU: fa referència al «Marco Español de Cualificaciones» o National Qualification Framework (NQF), que abasta tots els nivells, des del nivell 1 'd'Educació General Bàsica fins al 8 de doctorat universitari. El MECU, per tant, és el producte de la suma del Catàleg Nacional de Qualificacions Professionals (CNCP) i el Marc Espanyol de Qualificacions per a 'l'Educació Superior (MECES). deriva de la doble accepció del concepte d'innovació professional que hem revisat, que exposaré a continuació alguns elements que interpel-len avui la innovació educativa i específicament en el desplegament del rol docent a nivell universitari. Vagi, però, per endavant, que bona part de la meva reflexió la sostindria d'igual manera qualsevol que fos l'etapa formativa de referència, ja que aquest rol professional té en el seu eix substancial estructurador quelcom que va més enllà de l'etapa o institució on es desenvolupa. El que tenim en comú -i no parlo aquí d'aspectes laborals o estatutaris- un professor de l'etapa d'Educació Infantil o de Primària i un professor catedràtic d'Universitat, és molt més que el que ens separa. En la definició íntima i ètica de la nostra missió, només hi trobo coincidències, si parlem d'una docència professional i de qualitat.

"What we want is to see the child in pursuit of knowledge, and not knowledge in pursuit of the child».

George B. Shaw

\section{Reptes i principis de la innovació docent universitària avui, basats en evidències}

Basant-nos en el que hem desenvolupat en l'apartat anterior, la innovació docent universitària hauria de restar lluny i de manera equidistant tant de l'afirmació de continuar actuant d'una determinada manera «perquè les coses sempre s'han fet així», com de la falsa idea d'associar l'èxit de la innovació docent a l'adopció de posicions rupturistes o trencadores amb el passat, quasi en el terreny de les heroïcitats, perquè es pressuposa que ser innovador passa simplement per «fer les coses radicalment diferents de com s'han fet sempre». Ambdues posicions són insostenibles si ens interessa d'alguna manera l'èxit de la nostra aportació i missió educativa universitària. És tan inexplicable com reprovable avui en dia el manteniment sense més reflexió crítica del rol docent com a mer informant o transmissor de coneixement a l'alumne i basat fonamentalment en la comunicació oral unidireccional i transmissora a classe-més enllà que es puguin emprar campus on-line-, com el fet d'intentar desplegar de manera rupturista determinades estratègies hipotèticament innovadores de treball semipresencial, col-laboratiu i en xarxa fent ús d'un determinat espai virtual d'aprenentatge (EVA), sense més criteri que la hipotètica innovació que això suposa, però mancats de fonamentació pedagògica, orientació estratègica i de sentit final del canvi que es pretén dur a terme.

Lluny, doncs, d'aquests dos pols, allunyats entre ells però igualment erms, em disposo a concretar quines serien les línies rectores de caràcter psicopedagògic ara per ara internacionalment reconegudes com l'espai comú de la innovació docent universitària, basant-me en els principals resultats de la recerca psicopedagògica de les últimes dècades, com també, i per raons òbvies, en el potencial creixent de caràcter comunicatiu, relacional i de recerca d'informació que aporten les 
successives revolucions d'eines i espais de caràcter sociotecnològic, tant de caràcter individual com d'ús col-lectiu i en xarxa. Revisem a continuació determinats acords de caràcter internacional entorn de la necessària revisió i actualització psicopedagògica de la tasca docent.

\section{a) Sobre la naturalesa de l'aprenentatge: revisió de principis (OCDE)}

D'acord amb la Guia Professional sobre la «Naturalesa de l'aprenentatge» elaborada a partir del projecte «Entorns d'aprenentatge innovadors» (Dumont, Istance \& Benavides, 2010), liderat pel «Centre for Educational Research and Innovation» de la OCDE, és més que manifest que durant les darreres dècades l'aprenentatge ha anat adquirint protagonisme per raons diverses de molt pes. Com s'indica en l'informe referenciat, un primer factor ha estat l'abast dels canvis esdevinguts en el nostre món: la velocitat dels avenços en TIC, el pas cap a l'economia del coneixement i la importància que s'atribueix a les competències necessàries per a adaptar-s'hi. Les escoles i els sistemes d'ensenyament d'arreu del món han de reconsiderar el disseny i l'enfocament del seu propòsit fundador: l'ensenyament $i$ l'aprenentatge. ¿Com han de ser en ple segle xxi l'escolarització, l'ensenyament i, especialment, l'aprenentatge, en un món que canvia amb tanta rapidesa?

Alhora, la recerca empírica sobre com aprenen les persones, com es desenvolupen la ment i el cervell, com es formen els interessos i en què es diferencien les persones en tots aquests aspectes ha crescut enormement. Les ciències de l'aprenentatge, com a lloc de trobada interdisciplinari, destaquen la importància de «repensar allò que s'ensenya, com s'ensenya i com s'avalua», com a claus de la innovació docent que hem d'afrontar. I en aquest sentit confirmen principis clau com la consideració de l'alumnat en el centre de tot procés d'aprenentatge, com també la seva naturalesa social i emocional, al mateix temps que posen l'èmfasi en la necessitat d'una revisió global dels currículums des d'una perspectiva horitzontal i transversal, reduint fins on sigui possible la fragmentació del coneixement en micro-assignatures, acostant-se així a la realitat i a la seva complexitat interdisciplinària. I finalment es posa l'èmfasi també en les diferències individuals, l'esforç i l'avaluació continuada com a estratègia d'aprenentatge integral, i no com a control d'assoliment de continguts merament memorístics. Així, doncs, quan parlem del repte de la innovació docent, som davant d'un repte sistèmic i de caràcter interdisciplinari.

A partir, doncs, d'aquesta rellevant aportació de síntesi internacional, es deriven propostes d'innovació educativa a tots els nivells formatius, que abracen des de l'enfocament cooperatiu de l'aprenentatge fins als enfocaments basats en la investigació emmarcats en projectes complexos i rellevants que requereixen implicació constant, col-laboració, recerca i gestió de recursos. D'aquesta manera, plantejaments de l'aprenentatge basat en projectes, basat en problemes o aprenentatge mitjançant el disseny, esdevenen alter- natives crítiques a la docència estrictament magistral unidireccional i lluny de la implicació activa de l'estudiant en el procés com a constructor actiu dels aprenentatges.

I en aquest sentit últim, els enfocaments centrats en l'alumne que apliquen la tecnologia a l'aprenentatge apoderen l'estudiant i fomenten experiències d'aprenentatge positives que altrament no serien possibles. A més, la tecnologia i els nous entorns sociodigitals de l'aprenentatge ofereixen eines i espais molt rellevants per a la construcció compartida de coneixement, com també per al desplegament d'estratègies i recursos molt eficaços per potenciar els processos de personalització, l'aprenentatge cooperatiu, la gestió de l'avaluació formativa i els mètodes basats en la investigació.

No estem, per tant, davant d'un repte liderat per les tecnologies, sinó que aquestes s'alineen decisivament amb el canvi paradigmàtic psicopedagògic que exigeix la societat del segle Xxi i les noves competències a desenvolupar per part dels futurs professionals. Aquest gir, doncs, que comporta imaginar una nova escola, una nova Universitat, en consonància amb el que la societat espera d'aquestes institucions, capgira fins i tot esquemes clàssics del que s'espera que passi a les aules, respecte del que s'espera que passi a fora -es parla ja de «flipped classroom»- bo i interpel-lant els mateixos rols docent-discent. Efectivament, d'acord amb Francisco Longo, que citàvem en el preàmbul:

«Aquesta inflexió en el paradigma de l'ensenyamentaprenentatge transforma en profunditat el contracte psicològic amb els seus dos actors principals: estudiants i professors. Als primers, perquè els responsabilitza d'una part important del seu propi aprenentatge, imposant-los un paper més autònom i exigent del que estan acostumats a exercir. A més, una disposició més activa per la seva banda és consubstancial amb una manera d'aprendre, segons la qual la cocreació de coneixement, la col-laboració en reptes o projectes i el treball d'equip tenen un paper decisiu. Per a l'educand, l'estar al centre de l'escenari no equival a rebre el tracte obsequiós que es dispensa a un client. Al contrari, el seu nou rol l'obliga a superar certes pulsions (dispersió, superficialitat, individualisme, sobrevaloració, autoindulgència....). I si gestionar l'ajust d'expectatives és difícil, no ho és menys el que afecta el professorat. Com està passant en altres sectors, els professors estem-ens agradi o no-al llindar de canvis que transformen l'ofici que hem conegut. Canvien les competències exigibles: serà difícil que els processos de legitimació professional continuïn basant-se gairebé exclusivament en capacitats reconegudes per la comunitat acadèmica, però desvinculades moltes vegades del talent per a ensenyar. Canvien els rols docents, que hauran d'assegurar la qualitat dels aprenentatges $i$ integrar l'aptitud per dinamitzar-los, coproduir-los i connectar-los amb la realitat. Canvien certs requeriments d'habilitats tècniques, com les de comunicar en línia i desenvolupar continguts digitals, avui pràcticament inèdites. Canvien les mètriques i sistemes d'avaluació que hauran de reconèixer nous equilibris 
entre activitats presencials $i$ a distància i ponderar d'una manera diferent els esforços dedicats a preparar, actualitzar, impartir, orientar, monitorar, donar suport, avaluar, que formen part-molta o poca-dels contextos en què se socialitzen les persones arui en dia.» (Longo, 2015, El País).

\section{b) Sobre la formació en el rol docent: últims estudis europeus (TALIS, EURYDICE i EUROSTAT)}

Estem, doncs, els professors preparats per assumir aquest repte? Les últimes recerques i els estudis europeus al voltant de la tasca docent indiquen que no. Diversos estudis, com l'enquesta TALIS ${ }^{2}$ (Teaching and Learning International Survey, que aplica l'OCDE; específicament, cal esmentar la seva última aplicació l'any 2013) o l'últim informe de l'EURYDICE Network, «The Teaching Profession in Europe», les dades dels quals provenen de dades que es recullen sistemàticament en el marc de la xarxa EURIDYCE ${ }^{3}$ i també del proveïdor estadístic europeu d'EUROSTAT ${ }^{4}$, alerten entorn d'algunes circumstàncies preocupants. Tots ells coincideixen a afirmar que al voltant del $60 \%$ dels docents de Secundària europeus se senten ben preparats amb la formació que reben quant a contingut disciplinari, però aquest percentatge baixa al 40 \% quan es refereix als continguts pedagògics que se'ls faciliten per abordar el treball a l'aula. I, si concretem a nivell espanyol, els informes indiquen que un $75 \%$ dels docents es creuen correctament preparats pel que fa a continguts, però la proporció baixa al 37 \% quan es tracta de sentir-se segurs amb les estratègies i les eines pedagògiques.

Peter Birch, coordinador de política educativa i anàlisi de sistemes de la Comissió Europea, en el marc d'unes jornades organitzades per la Fundació Jaume Bofill, entorn de les «Perspectives Internacionals de l'Educació», celebrades el passat mes de desembre de 2015 , va afirmar que «els resultats dels informes europeus són un missatge contundent per a tothom», i va passar a preguntar-se què passaria i com reaccionaria la societat en general si aquest mateix nivell de percepció de preparació professional el tingués un cirurgià $\mathrm{o}$ un pilot d'avió. En aquest sentit va continuar afirmant: «No obstant això, deixem que aquests docents que es

\footnotetext{
${ }^{2}$ TALIS (Teaching and Learning International Survey) és un qüestionari que lidera i implementa l'OCDE al voltant dels processos d'ensenyament i aprenentatge a Secundària, des de l'any 2008. En el TALIS 2013 hi van participar 34 països, abastant temes importants com la formació inicial del professorat i el desenvolupament professional, el tipus d'avaluació i de retroalimentació que tenen els mestres, el clima de l'escola, el lideratge de l'escola, i l'anàlisi de les creences d'instrucció i les pràctiques pedagògiques dels docents.

${ }^{3}$ La xarxa EURYDICE de la Comissió Europea facilita la cooperació europea en l'àmbit de l'aprenentatge permanent i hi dóna suport, proporcionant informació sobre els sistemes i les polítiques educatives de 37 països i sobre l'elaboració d'estudis referents a les qüestions comunes als sistemes educatius europeus.

${ }^{4}$ EUROSTAT és l'oficina d'estadística de la Unió Europea situada a Luxemburg, la tasca de la qual és proporcionar a la Unió Europea estudis estadístics de diferents àmbits a nivell europeu que permetin comparacions entre països i regions. Per tant, la seva missió és ser el proveïdor líder d'estadístiques d'alta qualitat a Europa.
}

creuen poc preparats imparteixin classe als nostres fills a tots els nivells». I va afegir que, decisivament i definitivament, «s'ha de millorar la formació del professorat, tant la inicial com la contínua al llarg de la carrera professional».

Aquest mateix informe també recomana la necessitat de reforçar el desenvolupament professional dels docents i el compromís ètic amb l'educació com un bé comú, a més de progressar en la cooperació professional i en l'intercanvi de coneixement i de pràctiques innovadores entre el professorat europeu.

Però, si aquesta és la realitat a nivell de Secundària, altres estudis demostren que, a nivell universitari, el gap o bretxa existent entre el domini de continguts del professor universitari i el seu domini psicopedagògic basal que li ha de permetre desenvolupar el rol docent amb garanties suficients de qualitat per desplegar el seu rol docent en el marc de les exigències actuals, és superior. Es tracta d'una bretxa prou manifesta que, entre moltes altres raons, s'explica per la baixa o nul-la exigència prèvia d'aquesta fonamentació basal de caràcter psicopedagògic a la major part del cos universitari docent de la majoria d'universitats, a diferència del cos docent d'etapes anteriors, on almenys s'exigeix una titulació oficial prèvia, en format de Grau o Màster, per a poder començar a exercir, com és el cas del Grau de mestres per a Infantil o Primària, o el cas del Màster de Secundària, en el cas dels professors de Secundària. La Universitat -parlo en termes generals- sembla viure al marge, encara doncs, de la professionalització docent, segurament perquè encara no ha assumit de manera global que el rol del docent comporta un nivell de professionalització de gran complexitat, semblant al que exigim al professor universitari, el qual ha de demostrar un ampli domini de continguts d'una determinada matèria i un ampli domini del rol investigador al voltant d'aquesta. Però és clar que la concepció majoritària encara és la del supòsit que el domini de la «matèria» pressuposa la capacitat intuïtiva del desplegament professional docent entorn d'aquesta. Podríem dir, en certa manera, que la Universitat encara beu de les fonts del segle de les llums pel que fa al rol «docent», i paradoxalment i dissortadament, en canvi, ha perdut bona part de la fonamentació humanista que hauria d'emanar del mateix període històric si la impertorbabilitat de l'herència fos completa.

Sorprèn, sens dubte i en gran manera, el manteniment d'aquest gap històric al voltant del rol docent universitari i el seu manteniment o resistència al llarg dels temps.

És així que ressonen avui encara amb força les paraules pronunciades fa més d'un segle -en concret l'any 1905- per Miguel de Unamuno, llavors rector de la Universidad de Salamanca, en el marc de la Segona Assemblea Universitària que va tenir lloc a Barcelona, entre els dies 2 i 7 de gener de 1905, quan advertia que l'aparició de «la premsa» (equivalent en aquell moment al que avui anomenem INTERNET) obligava els professors universitaris a fer un pas endavant decidit, sota el risc de quedar-se obsolets o amb les classes buides: 
«El profesor debe abandonar su torre de marfil para ser «publicista», porque «la prensa» es hoy el verdadero campo de extensión universitaria; la prensa es hoy la verdadera Universidad popular». (../..) «Hace falta una modificación de raíz en el régimen legal de la enseñanza que sólo será posible cuando el profesorado universitario haya conseguido verter «nuevo vino de espíritu docente» en el viejo orden de las Universidades actuales. »

Per continuar dient amb lucidesa:

«...el profesor universitario no debe hacer doble empleo con el texto, y es hasta indecoroso el que se vaya a cátedra a recitar, durante una hora, lo que puede fácilmente hallarse en los libros de fácil acceso, o tal vez en un solo libro, y no pocas veces en el texto escrito por el recitador mismo. Esta es una mala costumbre que persiste, $y$, hay que confesarlo claramente, muy generalizada por desgracia y por vergüenza del profesorado universitario. Mientras ella subsista, no habrá razón justa para exigir a los alumnos el que asistan a clase, ya que en su casa pueden adquirir más cómodamente los conocimientos que en aquélla se les da» (Rabaté, 2009, IX, 140). ${ }^{5}$

De la mateixa manera que Unamuno intuïa (any 1905!) que, davant la socialització de la premsa escrita i els llibres, si no s'actualitzava la docència universitària no hi hauria raons per a demanar als alumnes que assistissin a classe, em pregunto què diria, ara, davant la revolució digital i l'aparició d'internet.

Certament no totes les universitats a Europa han reaccionat igual ni estan en el mateix nivell de desenvolupament davant aquest gran repte. Les divisions entre universitats de recerca i universitats considerades «docents» han accentuat aquestes asimetries. Les universitats mixtes -majoritàries a Europa- que integren equilibradament la triple missió (docent, recerca i transferència) són les que potser tenen el repte més gran, ja que la seva vocació és atendre amb excel-lència les tres funcions, i entre elles, naturalment, la docent. Però potser també el fet de combinar els valors de la triple hèlice pot revertir en el cercle virtuós del que parlàvem al principi d'aquest article. No hi ha una bona docència sense una bona recerca que fonamenti els seus coneixements, també els de caràcter psicopedagògic; no hi ha un bon docent sense una bona formació psicopedagògica prèvia i una bona capacitat reflexiva crítica, que, al mateix temps el porten a innovar i a transferir els seus coneixements a situacions concretes. Potser la clau de la docència universitària de futur, doncs, rau en tot això i en el fet de saber compartir aquest cercle virtuós amb els mateixos alumnes i des del primer moment, en lloc de situar-los passivament a l'espera d'explicar-los coses semblants i de la mateixa

${ }^{5}$ Rabaté, Colette; Rabaté, JEAN-CLAUDE (2009). MIQUEL de UNAMUNO. BIOGRAFIA. Taurus-Santillana Ediciones. Colección «Memorias y biografías». ISBN e-book: 978-84-306-1595-7. manera que fa un segle aproximadament, però ara, això sí, «penjant-ho tot» a l'EVA (Espai Virtual d'Aprenentatge). Poc hauríem avançat.

$$
\begin{array}{r}
\text { «n tiempos de cambio drástico, son los que } \\
\text { aprenden quienes heredan el futuro. } \\
\text { Los que «ya saben» suelen encontrarse muy bien } \\
\text { equipados para vivir } \\
\text { en un mundo que ya no existe» }
\end{array}
$$

Eric Hoffer

\section{Una mirada de futur: l'Escola i la Universitat del segle XXI}

Com ja hem compartit fins aquí, i en síntesi, afrontem, doncs, un canvi d'època en el món de l'educació, on la innovació traspassa l'antiga concepció de la introducció d'alguna nova tecnologia o d'alguna nova estratègia o tècnica d'aprenentatge. La transformació que afrontem interpel-la sistèmicament tots els elements estructuradors de l'acció educativa: la concepció del currículum, la didàctica, i els rols docent i discent. Evolucionem cap un model educatiu que, a partir dels aprenentatges instrumentals bàsics, estarà caracteritzat pel treball per projectes de caràcter social, col-laboratius, cooperatius, ludificats, i on les escoles o les universitats no seran el «reducte del coneixement i el saber», sinó el node de connexió crític, estructurador, personalitzador i dotador de sentit dels aprenentatges permanents, diversos i ubics que emanaran de la gran xarxa comunitària sociotecnològica d'aprenentatges.

L'evolució, doncs, va molt més enllà de la visió de les flipped classroom: estem parlant d'una autèntica transformació educativa en la qual la imatge de l'estudiant universitari no és la del que assisteix a classe -quan ho fa- per prendre uns apunts recitats -o tenir-ne fotocòpies o un PDF virtual-, i que es troba essencialment solitari davant dels apunts i uns llibres de text -si en llegeix-, sense cap passió manifesta pel seu aprenentatge i que afronta un seguit d'exàmens memorístics parcials per obtenir un aprovat final. Evolucionem ben lluny de tot això, sense que això signifiqui que no calgui un nivell d'esforç fins i tot superior per part de docents i discents. Però es tracta d'un esforç que s'arrela i busca un horitzó ple de sentit i apassionat pel coneixement i pel fet d'aprendre, no estrictament mediatitzat per l'obtenció d'una butlleta final sumatòria, sinó per l'assoliment d'unes competències professionals carregades de contingut, accions, actituds, valors i normes, i on l'avaluació forma part del procés d'aprenentatge d'una manera integral i desitjada per la mateixa voluntat d'aprendre. Un plantejament, doncs, centrat en l'aprenentatge i l'aprenent, que respongui el gran repte formulat per Delors, en els anys 90, d'equilibri de forces i esforços al llarg de tota la vida en el procés d'aprendre a conèixer, aprendre a fer, aprendre a viure junts i amb els altres, i aprendre a ser. Per tant, i d'acord amb Delors (1996), caldria que, mentre els sistemes educatius formals de tots els nivells 
formatius, incloent-hi la Universitat, continuen tendint a donar prioritat a l'adquisició de coneixements, en detriment d'altres formes d'aprenentatge, importa concebre l'educació com un tot. És, doncs, aquesta nova concepció del repte educatiu a tots els nivells $-\mathrm{i}$ que la mateixa reforma de Bolonya a nivell universitari va voler inspirar però que encara no ha assolit grans èxits destacables de transformació real significativa del que succeeix a les nostres aules europees- la que ens ha d'inspirar i orientar vers la necessària millora progressiva de l'ensenyament superior, i específicament en l'elaboració dels programes i en la implantació de noves polítiques pedagògiques universitàries per al segle xxI.

I tot això ho hem de fer assumint la nova coordenada de la velocitat dels canvis dels nous suports tecnològics de què ja disposem avui, i que anirem disposant amb el pas dels pròxims anys. Certament aquesta qüestió de l'acceleració en l'evolució de tots els recursos i serveis de suport disponibles, esdevé crítica si és que encara ens plantegem intentar «liderar» els processos d'ensenyament-aprenentatge en el marc d'una proposta formativa, abans que ens arrosseguin els mateixos canvis. I si, per raons òbvies, no és imaginable que aquest lideratge passi pel domini ple competencial del docent en l'ús i aplicació de totes les novetats sociotecnològiques que tenim i que anirem tenint a l'abast en endavant, en què consisteix aquest lideratge? Ben probablement la resposta rau en la nostra capacitat de ressituar el nou rol d'interaccions, propostes i demandes que podem $i$ hem de formular als nostres educands.

Les noves coordenades ens reposicionen el lloc des d'on eduquem, el contingut i el repte a formular, però no per això ens hem de convertir en docents ciberhumans. Cal comprendre la realitat present $i$ de futur dels nostres educands, i posar -més que el nostre coneixement- la nostra experiència amb el coneixement i la vida, a l'abast de l'aprenentatge dels nostres estudiants. És aquí on tot torna a tenir sentit, però un sentit nou. No som ja la font d'informació i d'acumulació de saber i de referència que cal imitar o evocar per superar la prova, sinó el nexe expert en els mapes conceptuals d'un àmbit de coneixement, i experts en l'experiència i vivència d'aquests. I, com a conseqüència, experts en la dotació de sentit dels nous aprenentatges. I per tot això, hem de projectar la revisió del nou rol docent lluny de la formulació de fílies o fòbies respecte dels successius avenços tecnològics que vivim i anirem vivint en endavant. Aquesta seria una gran trampa immobilitzadora.

La qüestió, doncs, no és ser més o menys experts en el domini de les noves tecnologies successives, sinó entendre el que aquestes aporten com a novetat transgressora i indefugible per tal de reinterpretar adequadament la nostra aportació docent professional, si volem continuar sent mestres o professors d'aquest món, avui. I la veritat és que, si realment estem vocacionats per a la recerca i la docència -no s'hauria d'esperar altra cosa d'un professional mestre o professor-, viure en aquests temps de transformació global, que impacten de ple en el nostre rol resulta del tot fascinant.

I és en aquest últim sentit, pel que fa als canvis que ja s'estan produint i als que estan a punt de produir-se, que és d'obligada referència citar dos informes recents de caràcter prospectiu: el primer, l'informe «La escuela del siglo XXI»' que ha realitzat Fundació Telefònica (VVAA, 2015) i que ha estat editat recentment, centrat específicament en una visió de present i futur del món educatiu escolar i d'instituts de Secundària, des d'una visió comparada de caràcter internacional; i el segon, l'informe «Horizon», centrat més específicament en les universitats i publicat recentment -l'any 2015-, fruit de la col-laboració entre el New Media Consortium ${ }^{6}$ i la xarxa EDUCAUSE Learning Initiative (ELI) ${ }^{7}$ intitulat: Horizon Report 2015: Higher Education Edition ${ }^{8}$.

Si els alumnes dels quals parla el primer dels informes -de molt recomanable lectura- són «reals» (que ja ho són) i resulta que els estem formant progressivament a nivell «no universitari», correm el risc que, quan arribin a la Universitat, tinguin la sensació que tornen a ser segles enrere, en el cas que aquesta Institució no faci passos decidits en la mateixa línia transformadora de la que ja hem parlat a bastament al llarg d'aquest article. És aquí on l'informe HORIZON ens ajuda a preveure aquestes evolucions en els paràmetres més elementals.

En concret, quan es tracta d'escatir quines són les tendències clau que acceleren l'adopció de la tecnologia educativa a les universitats, aquest informe les divideix en tres aproximacions temporals: a curt termini, a mitjà termini i a llarg termini. Revisem-les breument:

a) A curt termini (un o dos anys):

- L'evolució de l'aprenentatge en línia. Tot i el creixement constant i l'assentament de l'e-learning com a alternativa a algunes formes d'educació presencial, hi ha encara àrees d'investigació que poden comportar avenços importants: analítiques d'aprenentatge, aprenentatge adaptatiu, combinacions d'eines innovadores síncrones i asíncrones, etc.

- Replantejament dels espais d'aprenentatge. Noves formes d'aprenentatge com la classe inversa o flipped classroom han de comportar canvis en el disseny d'espais que ja s'estan duent a terme en moltes universitats. El paradigma de l'aprenentatge actiu requereix més mobilitat i flexibilitat i permet l'ús de múltiples dispositius. En aquest model, que s'encavalca amb l'aprenentatge mixt (blended learning) i amb enfocaments pedagògics actius, el temps de

${ }^{6}$ NMC: El New Media Consortium (http://www.nmc.org/). Des de la seva fundació l'any 1993, l'NMC s'ha centrat sempre en el tema següent: el futur i les implicacions de la tecnologia emergent a les escoles, als museus, a les universitats i a la societat.

${ }^{7}$ ELI: EDUCAUSE Learning Initiative és una xarxa internacional que pretén ajudar els qui condueixen, administren i utilitzen les tecnologies de la informació i les seves decisions estratègiques de TIC en tots els nivells dins l'Educació Superior. Vegeu-ho a: http://www.educause. edu/

${ }^{8}$ Vegeu-ho a: http://cdn.nmc.org/media/2015-nmc-horizon-report-HEEN.pdf 
classe es dedica a activitats d'aprenentatge collaboratives basades en projectes. El professor no transmet continguts a l'aula, sinó que utilitza videolliçons, podcasts, textos i fòrums en línia als quals l'estudiant accedeix abans i després de les classes.

b) A mitjà termini (de tres a cinc anys):

- Recursos educatius oberts. El valor del que és obert es va estenent progressivament. I obert no significa només gratuiit, sinó també copiable i reutilitzable sense límits per a usos educatius.

- Aprenentatge i avaluació basats en dades. S'espera que, a mesura que madurin el camp de les analítiques d'aprenentatge i el big data, la informació que proporcionin serveixi per a millorar l'avaluació contínua i els resultats educatius.

c) A llarg termini (cinc anys o més):

- Estratègies de canvi àgils. S'estén el consens entre les autoritats acadèmiques sobre la conveniència d'emprar metodologies àgils per a facilitar el canvi. La tecnologia pot servir com a catalitzadora d'una cultura de la innovació.

- Comunitats obertes i consorcis universitaris. La col-laboració i l'acció col-lectiva seran cada vegada més importants, entre altres raons per la reducció de costos que implica.

Per tant, el mateix informe conclou que els «reptes significatius» per a l'adopció de la tecnologia educativa a les universitats, passen, a curt termini, pel següent:

- L'alfabetització digital. S'imposa arribar a un acord sobre la definició de les noves habilitats afegides a la lectoescriptura clàssica. Sense aquest acord, serà molt difícil integrar l'alfabetització digital al currículum d'una manera efectiva i formular les polítiques adequades.

- També caldrà aprofundir en la relació entre l'aprenentatge formal $\mathbf{i}$ informal. Internet ha facilitat l'accés a la informació sobre qualsevol tema i ha augmentat l'interès per formes d'aprenentatge autodirigit i basat en la curiositat. La combinació d'aquest tipus d'aprenentatge informal amb l'ensenyament formal tradicional pot crear entorns que promoguin l'experimentació i sobretot la creativitat.

- I a un altre nivell d'anàlisi, cal afrontar el repte «morinià» de l'aprenentatge del pensament i la comunicació complexos. El món en què vivim requereix ser capaç no tan sols de pensar i entendre assumptes complexos, sinó també de comunicar aquesta informació complexa d'una manera comprensible. El web semàntic, les dades massives (big data) i les tecnologies de modelatge poden ajudar a assolir tot això $i$ també el repte de la màxima personalització de l'aprenentatge.

Finalment, i d'acord amb l'informe, els desenvolupaments importants que es preveuen pròpiament en «tecnologia» educativa per a les universitats són aquests:

A curt termini (un any o menys):

- Bring your own device (BYOD, «porta el teu propi dispositiu»). Portar el portàtil, la tauleta, el telèfon intel-ligent o altres dispositius mòbils a l'entorn de treball o aprenentatge és ja una pràctica habitual. Per tant, no es tracta només d'estalviar en la despesa en tecnologia, sinó sobretot d'aprofitar una realitat social que s'està imposant i donar solució als possibles problemes quant a seguretat informàtica, bretxa digital i neutralitat de plataformes.

A mitjà termini (de dos a tres anys):

- Makerspaces (tallers creatius). Tecnologies com la robòtica, les aplicacions de modelatge en 3D i les impressores 3D, han suposat un canvi de paradigma pel que fa a les habilitats que poden tenir una aplicació i un valor a la vida real. Els tallers en els quals s'ofereixen aquests tipus d'eines resulten molt rellevants per al redisseny dels espais d'aprenentatge i la seva ludificació (gamification).

- Tecnologia disponible (wearables). Els rellotges intelligents, les ulleres de realitat augmentada de Google i altres dispositius similars comencen a ser d'ús corrent $\mathrm{i}$ poden passar a formar part de l'experiència diària de moltes persones, de manera que també s'haurien de tenir en compte.

A llarg termini (de quatre a cinc anys):

- Tecnologies d'aprenentatge adaptatiu. Aquests sistemes d'intel-ligència artificial són capaços d'aprendre com aprenem les persones i adaptar els itineraris d'aprenentatge a les necessitats concretes de cada un. Es poden distingir dos nivells: segons que s'analitzin dades d'una persona individual o bé segons que s'analitzin dades agregades de mostres més extenses d'aprenents per tal de millorar el disseny del currículum.

- L'internet de les coses (The internet of things, IOT). La connexió de tot tipus d'objectes a la xarxa, mitjançant xips integrats, sensors, etc., crea enllaços entre el món físic i el web. A més del monitoratge i de la manipulació remots, això permet, per exemple, codificar objectes físics amb dades, descripcions, informació contextual, imatges, enllaços a altres objectes, etc.

Immergits, doncs, en tots aquests canvis, en els quals el «llarg termini» es conceptualitza només de quatre a cinc anys (!), cal continuar liderant els canvis des de l'acció educativa i no sotmetre'ns a l'indesitjable determinisme tecnològic. D'acord amb els plantejaments ja clàssics del sociòleg del segle passat William Ogburn (1922), hem de poder dissenyar en educació un bon desplegament de les quatre fases clàssiques d'incorporació de les noves tecnologies als usos socials: invenció, acumulació, difusió i ajust. Tal com va defensar Ogburn en el seu moment -molts sociòlegs actuals ho defensen encara com a sostenible-, sigui quina sigui la nova tecnologia que emergeix, la resposta social que té lloc en la fase d'ajust pot ser activa, original i no cal que sigui merament de recepció passiva, allunyant-nos així del temut determinisme tecnològic. I menys ens hauria de passar això en educació.

Principi aquest últim a tenir molt en compte en el present, i encara més si les tesis de Klaus Schwab sobre 
el futur immediat es van acomplint. Schwab, fundador i president executiu del World Economic Forum, afirma que, després de la «revolució digital» que estem vivint, emergeix ja una nova revolució tecnològica -la que ell anomena la «quarta revolució industrial»-, el desenvolupament de la qual serà tan ràpid que les etapes del seu desenvolupament se superposaran les unes a les altres.

Seguint Schwab (2015), i en particular citant l'anàlisi que dels seus postulats fa Santacana (2016) en el seu article «Un món en (plena) transformació», publicat per l'Àmbit Maria Corral, aquesta nova revolució industrial es diferencia de les anteriors en tres aspectes principals: la velocitat del seu desplegament, la interdisciplinarietat consubstancial i el fet que el canvi té lloc en sistemes complets. És a dir, que els nous canvis tecnològics es desenvoluparan molt més ràpidament que els actuals, de manera simultània i interactuant les diferents àrees de coneixement entre elles, i generant canvis a sistemes complets (per exemple, al sistema educatiu en la seva globalitat, contingut, objectius, dimensions i rols) i on la separació entre producció i consum es difumina. Si ho apliquem a l'educació, podem intuir com es difuminen també els rols educador-educand, en la seva condició d'igualació com a «aprenents al llarg de tota la vida» i amb el mateix món de la informació a l'abast de tots dos i uniformement. Això refermaria la tesi defensada al llarg d'aquest article, segons la qual el rol del docent ha d'estar més centrat en la comunicació de la seva experiència vital i d'expertesa en el camp de coneixement de referència, i la seva capacitat de comunicar-la i posar-la en interacció amb els processos d'aprenentatge dels estudiants, que no pas en la seva capacitat d'acumulació de continguts i d'evocació unidireccional davant els alumnes.

D'aquesta manera, els professors abandonen el seu rol merament tecnicoexecutor de programes i esdevenen líders dels processos holístics d'ensenyamentaprenentatge, constituint-se en autèntics «referents de sentit», comunicadors, mediadors i coconstructors de coneixement, lluny de representar un mer accés d'un homínid a determinats continents fragmentats de contingut o un últim i eriçat entrebanc avaluatiu a superar, per a l'obtenció d'un títol.

Finalitzem, doncs, citant Schwab, i proposant que aquesta màxima sigui d'aplicació i crida també al cos docent i d'educadors de tots els nivells educatius:

"In the end, it all comes down to people and values. We need to shape a future that works for all of us by putting people first and empowering them. In its most pessimistic, dehumanized form, the Fourth Industrial Revolution may indeed have the potential to «robotize» humanity and thus to deprive us of our heart and soul. But as a complement to the best parts of human nature-creativity, empathy, stewardship—it can also lift humanity into a new collective and moral consciousness based on a shared sense of destiny. It is incumbent on us all to make sure the latter prevails» (Schwab, 2015).

\section{Referències:}

Delors, J. (1996). Los cuatro pilares de la educación. Informe a la UNESCO de la Comisión internacional sobre la educación para el siglo XXI. Madrid:España.

Dumont, H., Istance, D. \& Benavides, F. (2010). The Nature of Learning: Using Research to Inspire Practice. OECD Publications.

Longo, F. (2015). Dando clase en la cubierta del Titanic. El País, 10 d'agost 2015. http://elpais.com/elpais/2015/08/03/opinion/1438612625_456169.html

Ogburn, W.F. (1922). Social change with respect to cultura and original nature. New York: B.W. Huebsch. Rabaté, C. \& Rabaté, J-C. (2009). Miguel de Unamuno. Biografía. Madrid: Taurus-Santillana.

Santacana, R. (2016). «Un món en (plena) transformació». Article publicat el 25 de gener de 2016 en el web institucional de l'Àmbit d'Investigació i Difusió Maria Corral. http://www.ambitmariacorral. org/2016/01/un-mon-en-plena-transformacio/

Schwab, K. (2015). «The Four Industrial Revolution: What it Means and How to Respond». A: ForeignAffairs.com 12 de desembre de 2015 i en el web del World Economic Forum 12 de gener de 2016. http:// www.weforum.org/agenda/2016/01/the-fourth-industrial-revolution-what-it-means-and-how-to-respond

VVAA (2015). La escuela del siglo XXI. Madrid: Fundación Telefónica.

\section{La innovación educativa en la Universidad y el nuevo rol docente}

Resumen. A lo largo de este artículo se revisa el concepto de innovación vinculado a cualquier profesión, sus acepciones e implicaciones de carácter deontológico. Esta introducción nos permite entrar de lleno en la innovación en el ámbito educativo y las coordenadas de máxima actualización psicopedagógica basadas en evidencias, en el desarrollo de la tarea docente en cualquier etapa educativa y específicamente de nivel universitario. Asimismo se revisa el estado de la formación inicial y permanente para el desarrollo de esta función profesional. Por último, se recuperan varios autores y los estudios más recientes en torno a la prospectiva de la educación y de la tarea docente a corto, medio y largo plazo, haciendo el análisis derivado de estas previsiones y de cómo todo ello impacta de lleno en el ejercicio profesional docente.

Palabras clave: innovación educativa; rol docente; innovación docente; enseñanza-aprendizaje; Universidad 
